UDC 528.242

\title{
DFHRS-BASED COMPUTATION OF QUASI-GEOID OF LATVIA
}

\author{
Inese Janpaule ${ }^{1}$, Reiner Jäger ${ }^{2}$, Ghadi Younis ${ }^{3}$, Jānis Kaminskis ${ }^{4}$, Ansis Zariņš ${ }^{5}$ \\ 1, 4, 5 Institute of Geodesy and Geoinformation, University of Latvia, Raina bulv. 19, LV-1586 Riga, Latvia \\ ${ }^{2}$ Faculty of Informationmanagement and Media, Institute of Geomatics, University of Applied Sciences, \\ Moltkestrasse 30, 76133 Karlsruhe, Germany \\ ${ }^{3}$ Palestine Polytechnic University, College of Engineering and Technology, Civil and Architectural Engineering, \\ Wade Alhareya, C Building, P.O.Box: 198, Hebron, Palestine \\ E-mails: ${ }^{1}$ inesej@inbox.lv (correspondingauthor); ${ }^{2}$ reiner.jaeger@web.de; ${ }^{3}$ ghadi@engineer.com; \\ janis.kaminskis@rtu.lv; ${ }^{5} a n s i s z x @ i n b o x . l v$
}

Received 07 February 2013; accepted 26 February 2013

\begin{abstract}
In geodesy, civil engineering and related fields high accuracy coordinate determination is needed, for that reason GNSS technologies plays important role. Transformation from GNSS derived ellipsoidal heights to orthometric or normal heights requires a high accuracy geoid or quasi-geoid model, respectively the accuracy of the currently used Latvian gravimetric quasi-geoid model LV'98 is $6-8 \mathrm{~cm}$. The objective of this work was to calculate an improved quasi-geoid (QGeoid) for Latvia. The computation was performed by applying the DFHRS software. This paper discusses obtained geoid height reference surface, its comparisons to other geoid models, fitting point statistics and quality control based on independent measurements.
\end{abstract}

Keywords: Geoid/Quasi-Geoid-Computation, GNSS Height Determination, Levelling.

Reference to this paper should be made as follows: Janpaule, I.; Jäger, R.; Younis, G.; Kaminskis, J.; Zarinš̌, A. 2013. DFHRS-based computation of quasi-geoid of Latvia, Geodesy and Cartography 39(1): 11-17.

\section{Introduction}

The objective of this work was to calculate the QGgeoid height reference surface for Latvia. The computation was performed by applying the DFHRS software of Karlsruhe University of Applied Sciences.

The obtained geoid height reference surface was then compared with Latvian gravimetric geoid model LV'98 which is broadly used by land surveyors for more than 10 years. It is based on gravimetric measurements, data digitized from gravimetric maps and satellite altimetry data over Baltic Sea, its computation was performed by applying GRAVSOFT software. The estimated accuracy of LV'98 geoid model is 6-8 cm (Kaminskis 2010).

Comparisons were made also between the geoid height reference surface obtained by using DFHRS software and EGG97, EGM2008, Eigen5c, Eigen6c, GOCE GO_CONS_GFC_2_DIR_R3 models, and between LV'98 and above mentioned regional and global models. Appropriate transformation was applied because the global models are not fitted to national height system.

\section{DFHRS software}

The DFHBF (Digitale Finite-Element Höhen-BezugsFläche) or DFHRS (Digital Finite-Element Height Ref- erence Surface) software (www.dfhbf.de), developed at the Karlsruhe University of Applied Sciences, Faculty of Geomatics (Jäger 1999) was used for computation of QGeoid height reference surface (HRS) of Latvia.

In the DFHRS concept the area is divided into smaller finite elements - meshes. The QGeoid HRS $l$ is calculated by a polynomial of degree $l$ in term of $(x, y)$ coordinates in each mesh indicated by index $k$ (Jäger 1999):

$N_{\text {DFHRS }}=\left\{\begin{array}{c}N\left(p_{k}\right)=\sum_{i=0}^{l} \sum_{j=0}^{l-i} a_{i j, k} \cdot y^{i} x^{j}=f^{T} \cdot p_{k} \\ C_{0,1,2}\left(p_{c} ; p_{d}\right)\end{array}\right\}$,

where $f$ is a design matrix and $p_{k}$ is a polynomial parameter matrix. The corresponding polynomial coefficients are introduced as $a_{i j, k}$ over $m$ meshes $(i=0, l$; $j=0, l ; k=1, m)$.

The surface between two neighboring meshes $c$ and $d$ should be continuous, so the continuity conditions are considered between elements to have a continuous surface with $C_{1}, C_{1}$ and $C_{2}$ continuity levels at the border line. The continuity level type $C_{0}$ implies equal func- 
tional values along each common mesh border. Level $C_{1}$ implies equal tangential planes and level $C_{2}$ implies equal curvature along the common borders of the QGeoid HRS model. Each group of meshes forms a patch. To reduce the effect of medium or long wave length systematic shape deflections in the QGeoid height observations $N$ and the vertical deflections $(\xi, \eta)$ from QGeoid or geopotential models (GPM), these observations are subdivides in a number of patches. Patches are formed depending on distribution of fitting points, each patch should contain at least 4 fitting points, which are necessary for a datum parameter estimation. The patches are related to individual sets of datum parameters, in order to model the long-wavelength systematic errors from QGeoid or GMP.

The calculated continuous polynomial parameters are stored together with the mesh topology information in a DFHRS-DB database. The DFHRS computed height $N$ is provided by means of this database, which contains the QGeoid HRS parameters together with mesh and patch design information.

The mathematical model for computation of DFHRS-DB parameters is described by (Jäger et al. 2012).

\section{Computation process}

As an input data $(N, \xi, \eta)$ the European Gravimetric Geoid Model 1997 (EGG97) was used. EGG97 is based on high-resolution gravity and terrain data available in 1997 as well as the global geopotential model EGM96 (Denker, Torge 1998). The geoid undulations and vertical deflections for 25 points in each mesh from EGG97 model were introduced as observations in the DFHBF approach and software.

102 GPS/levelling points $(B, L, h \mid H)$ - serving both as fitting points for the QGeoid surface as well as the datum parameter-estimation of the patches - with known ellipsoidal GNSS heights $h$ and normal heights $H$ were introduced. Most of the fitting points are located within territory of Latvia, 3 points in Estonia and 17 points in Lithuania.

The designed mesh size is $5 \times 5 \mathrm{~km}$, so the total number of meshes is 4601 in the computation area. The patch size varies depending on distribution of reference points (from $80 \times 40 \mathrm{~km}$ to $150 \times 100 \mathrm{~km}$ ). In Fig. 1 the thin blue lines represent meshes, the thick blue lines - the patch borders and the green triangles - the fitting points.

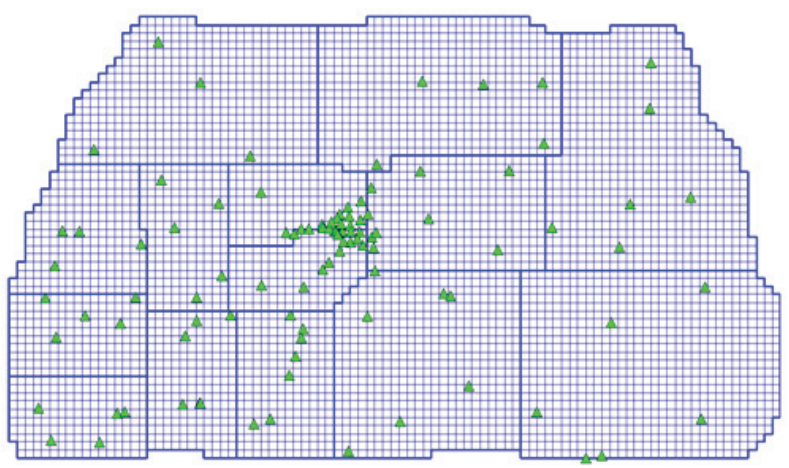

Fig. 1. Computation design for Latvia DFHRS-DB
DFHRS software provides internal quality control of the fitting points. The functional models mean an overdetermined system of equations with respect to the parameters, and require parameter estimations for redundant equation systems. The DFHRS software solves the respective parameter estimation by a Least Squares Adjustment. Based on Least Squares Adjustment the quality control and the quality indicators are set up as statistical tests (data snooping) for all single observations in the DFHBF-software.

The computation of Latvia QGeoid HRS was repeated three times, removing fitting points with detected residuals exceeding $3 \mathrm{~cm}$ after first and second computation. Most of the removed fitting points are located in North-West part of Latvia, in Kurzeme region (Fig. 2).

3rd order polynomials for the HRS meshes parameterization were used on all computations. Both geoid undulations (115025) and vertical deflections (230050) from EGG97 model were included as mesh observations. The number of continuity conditions was 65227, the number of unknown polynomial parameters was 46010 and the redundancy number was 364311 .

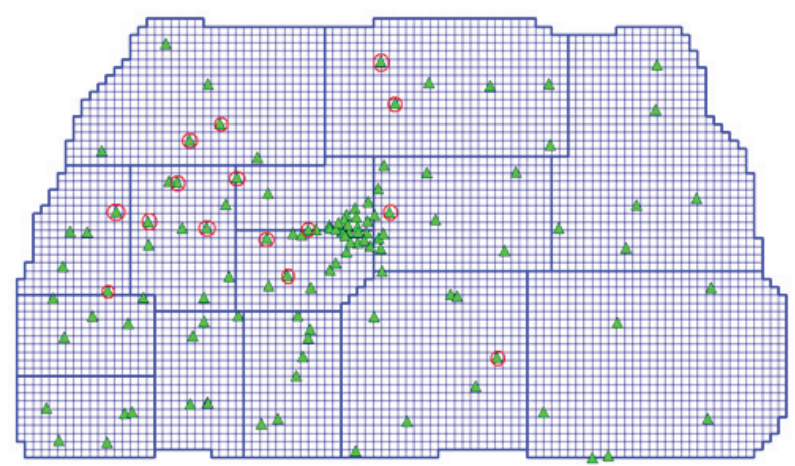

Fig. 2. Removed fitting points (red circles)

\section{QGeoid computation results}

The resulting QGeoid model is presented on Fig. 3. QGeoid heights in the territory of Latvia vary from $19.20 \mathrm{~m}$ in North-East part to $24.50 \mathrm{~m}$ in South-West part.

For the quality control of obtained QGeoid HRS result, it was tested using the same 102 GPS/levelling points which were used during DFHRS computation. The same test was performed for LV'98 QGeoid mod-

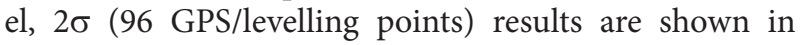
Table 1. Residual RMS of $1.6 \mathrm{~cm}$ for Latvian QGeoid HRS was obtained. The same RMS appears for LV'98 QGeoid model, however the minimum and maximum values are larger than those in DFHRS solution.

Table 1. Fitting point statistics ( $2 \sigma-95 \%$ of fitting points)

\begin{tabular}{|l|l|l|l|}
\hline & Min $(\mathrm{m})$ & Max $(\mathrm{m})$ & RMSE $(\mathrm{m})$ \\
\hline DFHRS & $-0,036$ & 0,034 & 0,016 \\
\hline LV'98 & $-0,042$ & 0,040 & 0,016 \\
\hline
\end{tabular}

For comparison between LV'98 model and DFHRS solution (Fig. 4), minimum difference is $-25.7 \mathrm{~cm}$, maximum: $21.1 \mathrm{~cm}$, RMS: $5.8 \mathrm{~cm}$. 


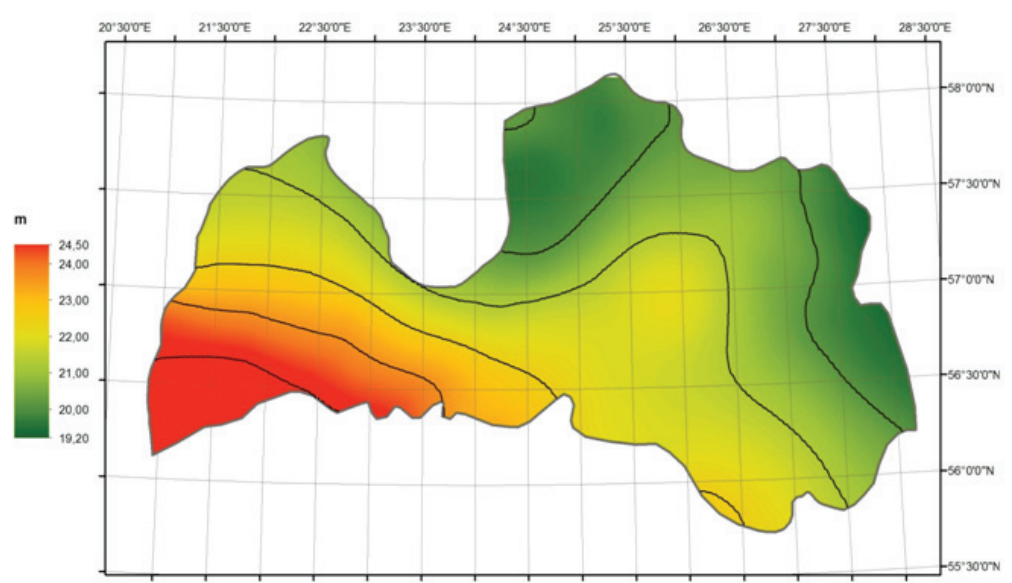

Fig. 3. Obtained QGeoid height reference surface for the territoy of Latvia

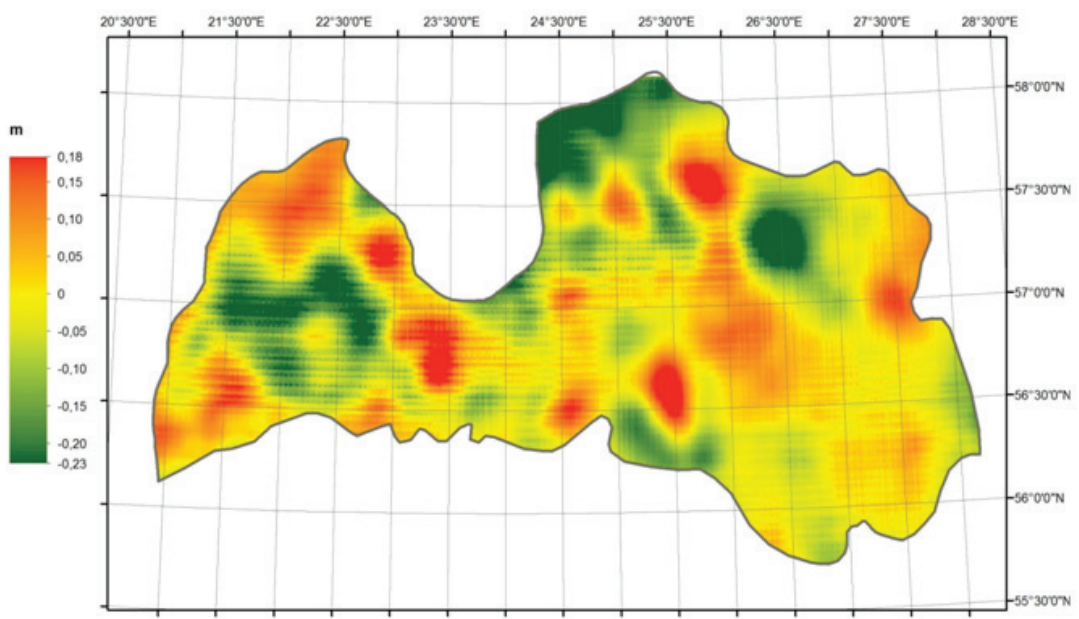

Fig. 4. Difference between LV'98 and DFHRS solution

\section{Comparison with EGG97 and Global Geopotential Models}

Because the global models are not fitted to national height system, following transformation was performed:

$$
\begin{aligned}
& h-H=N_{G}-[[\cos (L) \cdot \cos (B)] . \\
& \left(u-u_{G}\right)+[\cos (B) \cdot \sin (L)] \cdot\left(v-v_{G}\right)+[\sin (B)] . \\
& \left(w-w_{G}\right)+\left[e^{2} \cdot N \cdot \sin (B) \cdot \cos (B) \cdot \sin (L)\right] . \\
& \left(e_{x}-e_{x, G}\right)+\left[-e^{2} \cdot N \cdot \sin (B) \cdot \cos (B) \cdot \cos (L)\right] . \\
& \left.\left(e_{y}-e_{y, G}\right)+\left[h+W^{2} \cdot N\right] \cdot \Delta m+\left[N_{G}+W^{2} \cdot N\right] \cdot \Delta m_{G}\right]
\end{aligned}
$$

where point position is represented by geographical latitude and longitude $(B, L), h$ is ellipsoidal height, $H$ is orthometric height, $N_{G}$ is geoid height, $N$ is normal radius of curvature, $W=a / N, e^{2}=2 f-f^{2}(a=$ main axis $f=$ flattening of reference ellipsoid GRS80), three translations $\left(u-u_{G}, v-v_{G}, w-w_{G}\right)$, two rotations $\left(e_{x}-e_{x, G}, e_{y}-e_{y, G}\right)$ in horizontal plane and scale difference $\left(\Delta m, \Delta m_{G}\right)$ are present (Jäger 1999).
For the transformation of European Gravimetric Geoid Model 1997 and global geopotential models to national height system, 13 fitting points evenly distributed within territory of Latvia were introduced.

After the fitting of EGG97 and GGM's, the comparisons between EGG97, EGM2008 (Pavlis et al. 2008), Eigen5c (Förste et al. 2008), Eigen6c (ICGEM), GOCE GO_CONS_GFC_2_DIR_R3 (Brunisma et al. 2010) models and LV'98, as well DFHRS solution, were made. The results are shown in Table 2.

The comparison with global models shows that LV'98 model and DFHBF solution has the best agreement with EGG97 and EGM2008 - RMS is $4-6 \mathrm{~cm}$. Because EGG97 model was implemented in DFHRS solution, its RMS is $1.7 \mathrm{~cm}$. GO_CONS_GFC_2_DIR_R3 model contain satellite only information, derived from the tracking of artificial Earth satellites - Goce, Grace and Lageos. This satellite only model has the worst agreement with both LV'98 and DFHRS solution. Some of the comparisons are shown in Figs. 5 and 6.

Similar statistic results were obtained using the same 102 GPS/levelling points which were used during DFHRS computation for datum definition. $2 \sigma$ (96 GPS/ levelling points) results are shown in Table 3. 
a)

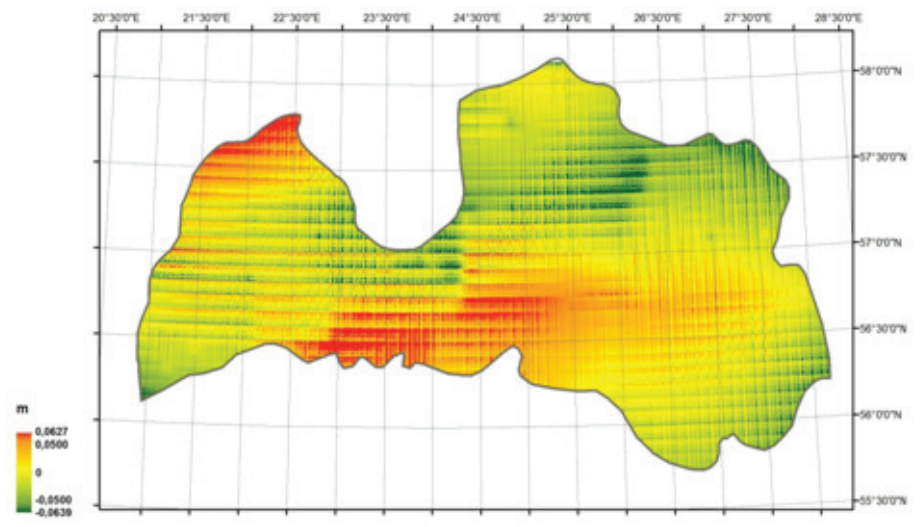

b)

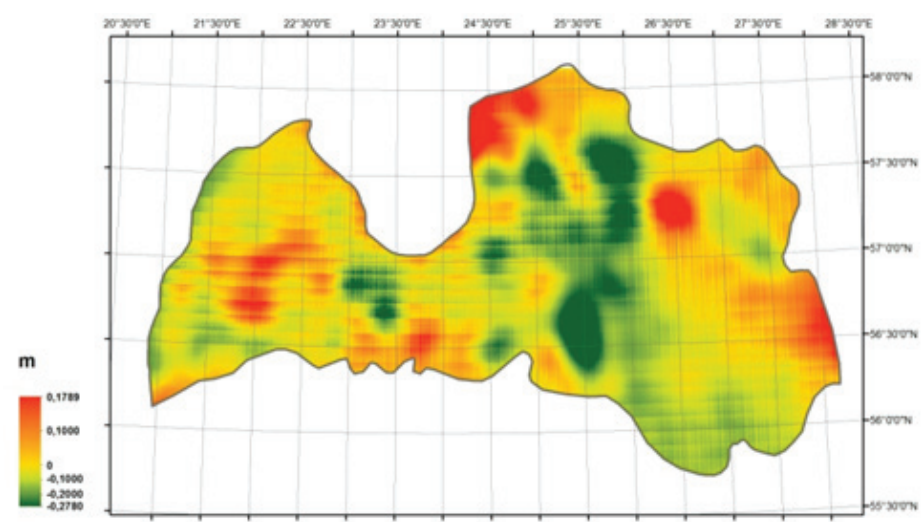

Fig. 5. Differences between DFHRS and EGG97 (a), DFHRS and EGM2008 (b)

a)

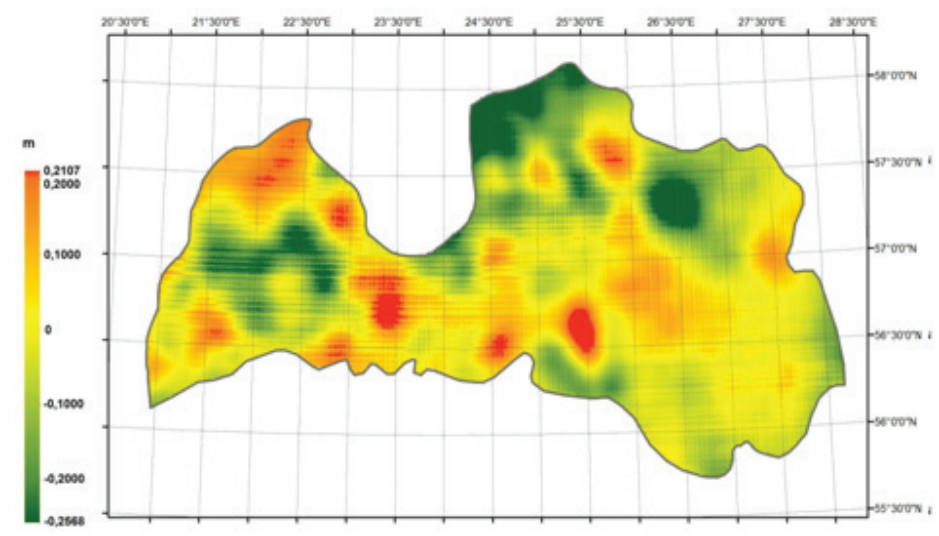

b)

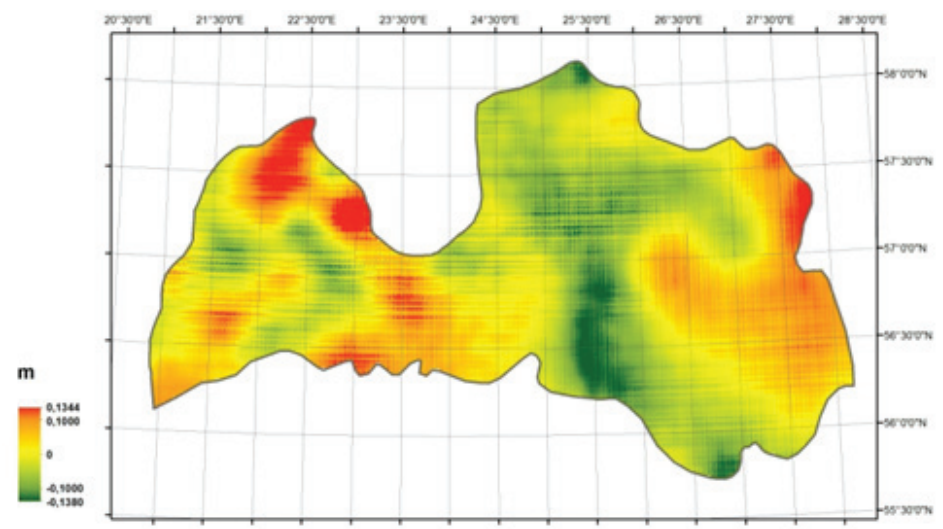

Fig. 6. Differences between LV'98 and EGG97 (a), LV'98 and EGM2008 (b) 
Table 2. Comparison with EGG97 and Global Geopotential Models

\begin{tabular}{|c|c|c|c|c|}
\hline & $\operatorname{Min}(\mathrm{m})$ & $\operatorname{Max}(\mathrm{m})$ & Average (m) & RMS (m) \\
\hline DFHRS-EGG97 & $-0,064$ & 0,063 & $-0,013$ & 0,017 \\
\hline DFHRS-EGM2008 & $-0,278$ & 0,179 & $-0,046$ & 0,052 \\
\hline DFHRS-Eigen6c & $-0,233$ & 0,188 & 0,005 & 0,064 \\
\hline DFHRS-Eigen $5 c$ & $-0,206$ & 0,672 & 0,130 & 0,115 \\
\hline DFHRS-GO_CONS_GFC_2_DIR_R3 & $-0,460$ & 1,030 & 0,381 & 0,266 \\
\hline LV’98-EGG97 & $-0,257$ & 0,211 & 0,000 & 0,058 \\
\hline LV'98-EGM2008 & $-0,138$ & 0,134 & $-0,033$ & 0,044 \\
\hline LV'98-Eigen6c & $-0,203$ & 0,201 & 0,018 & 0,063 \\
\hline LV’98-Eigen $5 c$ & $-0,211$ & 0,480 & 0,142 & 0,123 \\
\hline LV'98-GO_CONS_GFC_2_DIR_R3 & $-0,461$ & 1,077 & 0,393 & 0,272 \\
\hline
\end{tabular}

Table 3. Fitting point statistics for EGG97 and Global Geopotential Models ( $2 \sigma-95 \%$ of fitting points)

\begin{tabular}{l|l|l|l}
\hline & $\begin{array}{l}\text { Min } \\
(\mathrm{m})\end{array}$ & $\begin{array}{l}\text { Max } \\
(\mathrm{m})\end{array}$ & $\begin{array}{l}\text { RMS } \\
(\mathrm{m})\end{array}$ \\
\hline EGG97 & $-0,078$ & 0,074 & 0,037 \\
\hline EGM2008 & $-0,085$ & 0,079 & 0,042 \\
\hline Eigen6c & $-0,151$ & 0,125 & 0,055 \\
\hline Eigen5c & $-0,162$ & 0,317 & 0,153 \\
\hline GO_CONS_GFC_2_DIR_R3 & $-0,662$ & 0,745 & 0,346 \\
\hline
\end{tabular}

\section{Quality control based on independent measurements}

Table 4 shows three levelling control points, which were not used for the computation of Latvian QGeoid HRS. An example of quality control of Moldova QGeoid HRS is presented at (Jäger 2010). The GNSS control measurements were performed on 14 December
2012. by geodesists of Latvia University of Agriculture, Faculty of Rural Engineering, as a static 4 hour mea-

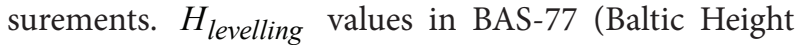
System 1977) are obtained from Latvian Geospatial Information agency database. Point No 1636 is located in North-West part of Latvia, point No 1155 is located in West central part and point No 1727 is located in central part of Latvia. Table 4 gives an overview of the results of GPS control measurement comparison of $H_{\text {levelling }}$ and $h_{\text {ellipsoidal }}$ with $N_{D F H R S}$. Differences between $H_{\text {levelling }}$ and $H_{G N S S}=h_{\text {ellipsoidal }}-N_{\text {DFHRS }}$ are between $0 \mathrm{~cm}$ to $2.6 \mathrm{~cm}$.

\section{Detection of height deformations in the area of Riga using the DFHRS database}

11 levelling control points, which were not used for the computation of Latvian QGeoid HRS, were selected in

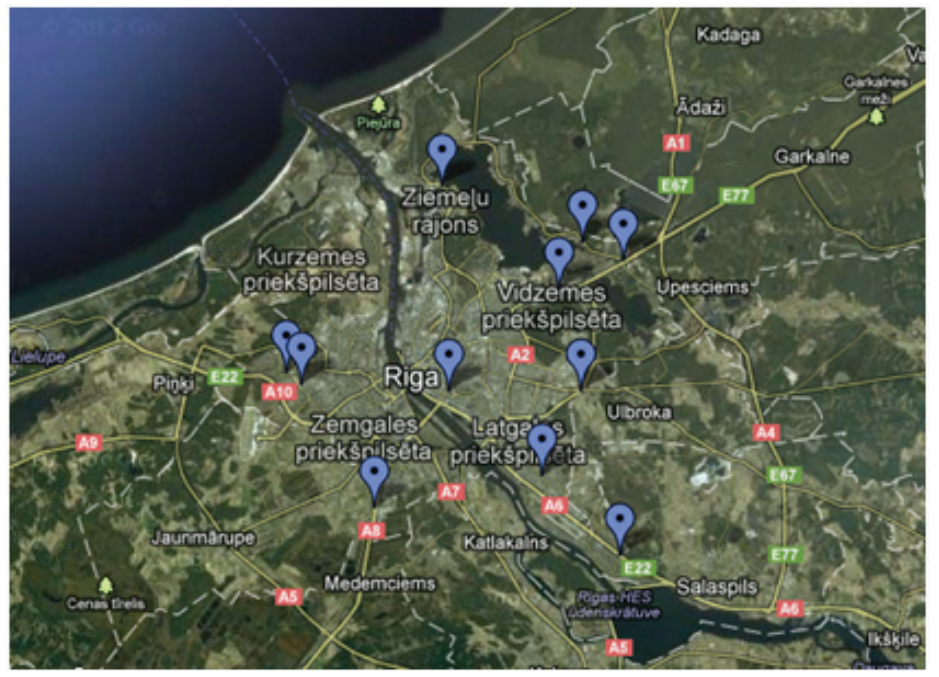

Fig. 7. Selected independent levelling control points in Riga city

Table 4. $1^{\text {st }}$ order leveling benchmarks for quality control

\begin{tabular}{l|c|c|c|c|c|c|c}
\hline $\begin{array}{l}1^{\text {st }} \text { order levelling } \\
\text { benchmark name, No }\end{array}$ & $\begin{array}{c}\text { Year of } \\
\text { levelling }\end{array}$ & Latitude & Longitude & $\begin{array}{c}\mathrm{h}_{\text {ellipsoidal }} \\
(\mathrm{m})\end{array}$ & $\begin{array}{c}\mathrm{H}_{\text {levelling }} \\
(\mathrm{m})\end{array}$ & $\begin{array}{c}\mathrm{N}_{\text {DFHRS }} \\
(\mathrm{m})\end{array}$ & $\begin{array}{c}\text { Difference to } \\
(\mathrm{m})\end{array}$ \\
\hline Mērsrags, 1636 & 2007 & 57,38516 & 22,97266 & 27,620 & 6,890 & 20,704 & 0,026 \\
\hline Vāne, 1155 & 2007 & 56,94707 & 22,44686 & 116,975 & 94,480 & 22,495 & 0,000 \\
\hline Eleja, 1727 & 2005 & 56,41508 & 23,69842 & 55,359 & 32,380 & 23,001 & $-0,022$ \\
\hline
\end{tabular}


Table 5. Levelling benchmark measurement comparison to DFHRS computed QGeoid HRS values

\begin{tabular}{|c|c|c|c|c|c|c|}
\hline Point No & Latitude & Longitude & $\begin{array}{l}\mathrm{h}_{\text {ellipsoidal }} \\
\text { (m) }\end{array}$ & $\begin{array}{c}\mathrm{H}_{\text {levelling }(1977)} \\
(\mathrm{m})\end{array}$ & $\begin{array}{c}\mathrm{N}_{\text {DFHRS }} \\
(\mathrm{m})\end{array}$ & $\begin{array}{l}\text { Difference to } \mathrm{N}_{\text {DFHRS }} \\
(\mathrm{m})\end{array}$ \\
\hline 5715 & 56,90561 & 24,21107 & 32,890 & 11,811 & 21,116 & $-0,037$ \\
\hline 1193 & 56,86987 & 24,27417 & 31,844 & 10,566 & 21,258 & 0,020 \\
\hline 915 & 56,94540 & 24,01676 & 32,804 & 11,823 & 21,036 & $-0,055$ \\
\hline 3389 & 56,89100 & 24,07539 & 33,490 & 12,314 & 21,213 & $-0,038$ \\
\hline 8540 & 57,03301 & 24,13018 & 30,232 & 9,623 & 20,682 & $-0,072$ \\
\hline 37 & 57,00825 & 24,24445 & 27,707 & 7,042 & 20,728 & $-0,063$ \\
\hline 938 & 57,00033 & 24,27682 & 34,027 & 13,328 & 20,756 & $-0,058$ \\
\hline 3336 & 56,94287 & 24,24295 & 30,359 & 9,439 & 20,976 & $-0,056$ \\
\hline T8 & 56,94285 & 24,13518 & 25,691 & 4,746 & 20,997 & $-0,052$ \\
\hline 0895 & 56,95117 & 24,00392 & 29,418 & 8,415 & 21,021 & $-0,017$ \\
\hline \multirow[t]{2}{*}{868} & 56,98750 & 24,22432 & 29,513 & 8,736 & 20,814 & $-0,037$ \\
\hline & & & & & $\begin{array}{l}\text { Mean Systematic } \\
\text { Difference }\end{array}$ & $-0,0489$ \\
\hline
\end{tabular}

Riga city territory (Fig. 7). These points are considered as the most stable Riga city levelling network points (ground benchmarks), $H_{\text {levelling(1977) }}$ values are taken from $2^{\text {nd }}$ order levelling network catalogue of years 1975-1977, $h_{\text {ellipsoidal }}$ values were obtained during RTK measurements in 2010 (Balodis et al. 2011).

Table 5 gives an overview on the sites of the GNSS RTK measurement and levelling catalogue value comparison to DFHRS computed QGeoid HRS values. The mean difference of this comparison reaches $-4.9 \mathrm{~cm}$. However, since 1977, Riga levelling network has not been controlled. According the investigation of (Silabriedis 2012) the Riga leveling network has experienced significant deformations. Table 5 shows that height differences between $H_{G N S S}=h_{\text {ellipsoidal }}-N_{D F H R S}$ and $H_{\text {levelling(1977) }}$ reflect the height deformations of $5 \mathrm{~cm}$ subsidence since years 1975-1977.

\section{Conclusions}

QGeoid height reference surface for Latvia of RMS $1.6 \mathrm{~cm}$ was obtained using DFHBF software. In case of poor coverage of fitting point data it is possible to change input parameters (mesh and patch size) of DFHBF software to obtain better accuracy. High accuracy geoid height reference surface can be achieved by minimum number of observations (102 fitting points). The DFHBF software version 5 (www.dfhbf.de) will also be able to handle terrestrial gravity observations in the integrated Least-Squares-Adjustment approach, which can - in opposite to the Stokes approach - be controlled each by data-snooping. The comparisons with Global Geopotential Models and fitting point quality assessment show that the high resolution and integrated EGM2008 has the agreement with both LV'98 and new DFHBF based solution.

Currently the project of digital zenith camera and its control software for vertical deflection measurements is under development at the University of Latvia, Institute of Geodesy and Geoinformation (Ābele et al. 2012). After obtaining first vertical deflection measurements, these will be used for an update of the new Latvian QGeoid model solution, using again the DFHBF software.

\section{Acknowledgement}

This research was funded by ERDF, project Nr 2010/0207/2DP/2.1.1.1.0/APIA/VIAA/077 and FP7 project "FOTONIKA-LV - FP7-REGPOT-CT-2011285912". Authors wish to thank Prof. J. Balodis for his advice and support during this research.

\section{References}

Ābele, M.; Balodis, J.; Janpaule, I.; Lasmane, I.; Rubans, A.; Zariňš, A. 2012. Digital Zenith camera for vertical deflection determination, Geodesy and Cartography 38(4): 123-129. http://dx.doi.org/10.3846/20296991.2012.755324_

Balodis, J.; Balodis, K.; Janpaule, I.; Kaminskis, J.; Normand, M.; Mitrofanovs, I.; Plotnikovs, S.; Rubans, A.; Silabriedis, G.; Zvirgzds, J. 2011. On road of "EUPOS" Contribution to GOCE Mission", in International Symposium on Global Navigation Satellite Systems, Space-Based and Ground-Based Augmentation Systems and Applications, Brussels, Belgium, 29-30 November 2010: conference proceedings. Berlin: Senate Department for Urban Development, 47-50. ISBN 978-3-938373-94-1.

Brunisma, S. L.; Marty, J. C.; Balmino, G.; Biancale, R.; Forste, C.; Abrikosov, O.; Neumayer, H. 2010. GOCE gravity field recovery by means of the direct numerical method, in ESA living Planet Symposium 2010, 27 June - 2 July, 2010, Bergen, Norway.

Denker, H.; Torge, W. 1998. The European gravimetric quasigeoid EGG97 - an IAG supported continental enterprise, International Association of Geodesy Symposia 119: 249254. http://dx.doi.org/10.1007/978-3-642-72245-5_36

Förste, C.; Flechtner, F.; Schmidt, R.; Stubenvoll, R.; Rothacher, M.; Kusche, J.; Neumayer, H.; Biancale, R.; Lemoine, J-M.; Barthelmes, F.; Bruinsma, S.; Koenig, R.; Meyer, U. 2008. EIGEN-GL05C - a new global combined high-resolution 
GRACE-based gravity field model of the GFZ-GRGS cooperation, EGU general assembly 2008, Geophysical Research Abstracts 10, abstract No. EGU2008-A-06944.

International Center for Global Earth Models (ICGEM), GeoForschungsZentrum Potsdam (GFZ). Table of Available Models [online], [cited 07 February 2013]. Available from Internet:

http://icgem.gfz-potsdam.de/ICGEM/ICGEM.html

Jäger, R.; Kaminskis, J.; Strauhmanis, J.; Younis, G. 2012. Determination of Quasi-Geoid as height component of the geodetic infrastructure for GNSS-positioning services in the Baltic States, Latvian Journal of Physics and Technical Sciences 49(3): 5-15.

Jäger, R. 2010. Results of the GNSS-Heighting Test-Measurements based on the country-wide Quasi-Geoid „DFHBF_ V1.0 Baltic-Sea-1977 for Moldova“, in BMBF-Research and Development Project MOLDPOS.

Jäger, R. 1999. State of the art and present developments of a general concept for GPS-based height determination, in Proceedings of the First Workshop on GPS and Mathematical Geodesy in Tanzania (Kilimanjaro Expedition 1999). Dar Es Salaam: University College of Lands and Architectural Studies (UCLAS).

Kaminskis, J. 2010. Geoid model for surveying in Latvia, in International FIG Congress 2010, FS 1C, 11-16 April, 2010, Sydney, Australia [online], [cited 07 February 2013]. Available from Internet: www.fig.net/pub/fig2010/papers/fs01cl fs01c_kaminskis_4066.pdf_

Pavlis, N. K.; Holmes, S. A.; Kenyon, S. C.; Factor, J. K. 2008. An earth gravitational model to degree 2160: EGM2008, EGU general assembly 2008, Geophysical Research Abstracts 10, abstract No. EGU2008-A-01891

Silabriedis, G. 2012. Eupos-Rīga Geodetic Reference Network and its Multifuncional Application: Doctor's dissertation. Riga: Riga Technical University. ISBN 978-9934-507-21-2.
Inese JANPAULE. Ph.D. student at the Institute of Geodesy and Geoinformation, University of Latvia, Raina bulv. 19, LV-1586 Riga, Latvia.Ph +371 67034435, e-mail: inesej@inbox.lv. Graduate of Riga Technical University (Mg. sc. ing. 2008). Research interests: GNSS, land surveying, Bernese GNSS software applications.

Reiner JÄGER. Prof. Dr, Ing. Course Director of International Study programme Geomatics, Institute of Geomatics, Faculty of Informationmanagement and Media, University of Applied Sciences, Moltkestrasse 30, 76133 Karlsruhe, Germany. Ph +49 0721925 2620, e-mail: reiner.jaeger@web.de. (Dr phys. 1988).

Research interests: satellite geodesy, mathematical geodesy, physical geodesy, adjustment, software development, GNSS/ MEMS multisensor navigation, physical geodesy.

Ghadi YOUNIS. Lecturer at Palestine Polytechnic University, College of Engineering and Technology, Civil and Architectural Engineering Department, Wade Alhareya C Building, P.O.Box: 198, Hebron, Palestine. Ph +972 2 2233050, e-mail:ghadi@engineer.com.

Graduate of University of Applied Sciences (Mg. sc. 2006), Ph.D. studies at TU-Darmstadt (2008-2013).

Research interests: satellite geodesy, mathematical geodesy, gravity field modeling (q/geoid), software development.

Jānis KAMINSKIS. Associate professor and leading researcher of Institute of Geodesy and Geoinformation, University of Latvia, Raina bulv. 19, LV-1586 Riga, Latvia. Ph +371 27476220, e-mail: janis.kaminskis@gmail.com. (Dr phys. 2010).

Research interests: fundamental and satellite geodesy, geodynamics, GNSS networks and application, gravity field modeling (q/geoid) and astronomy.

Ansis ZARIN̦Š. Leading researcher at the Institute of Geodesy and Geoinformation, University of Latvia, Raina bulv. 19, LV-1586 Riga, Latvia ( $\mathrm{Ph}+371$ 67034435), e-mail: ansiszx@inbox.lv. (Dr phys. 1988).

Research interests: control and data processing systems for satellite observation and astrometric instruments. 